\title{
Effective Leadership Styles
}

\author{
Kavitha Sethuraman ${ }^{1} \&$ Jayshree Suresh ${ }^{1}$ \\ ${ }^{1}$ School of Management, SRM University, Tamilnadu, India \\ Correspondence: Kavitha Sethuraman, School of Management, SRM University, Kattankulathur 603203 , \\ Kanchipuram, Tamilnadu, India. E-mail: kavitha1823@gmail.com
}

Received: July 15, 2014

doi:10.5539/ibr.v7n9p165
Accepted: August 4, 2014

Online Published: August 25, 2014

URL: http://dx.doi.org/10.5539/ibr.v7n9p165

\begin{abstract}
On Leadership there are various theories developed. One amongst them is a personality trait theory which is built on inherent internal characteristics. There is no one answer on "Do inborn preferences influence leadership style?" There are tools like Myers Briggs Type Indicator (MBTI) to measure the leadership traits. The personality types influences the leadership styles which leads to appropriate, under or over leading and the readiness of the followers to receive the direction. An effective leadership style can be developed on the basis of understanding of the situations. This paper develops a conceptual model about the relationship and an empirical study. Data was collected from managers trained in Situational Leadership which consisted of an independent training on Meyers and Brigs type indicator to understand their preferences and a 360 degree feedback on their leadership styles .The results confirmed the modern theory that leadership is not only inborn but can be developed if one focuses on the inborn preferences,
\end{abstract}

Keywords: MBTI, situational, leadership, effective leadership

\section{Introduction}

A leader is defined as a person with the responsibility to influence one or more followers and directing them to achieve a set objective. While doing so, the leader has to be aware of the strength of each of his follower and identify the areas to be improved (Bruce E. Winston and Kathleen Patterson, 2006). A leader should be able to change his or her leadership style based on the situation in order to be more effective, focus on supporting the followers and build their trust and respect (Aric Hall, 2007). Literatures have stated that the key elements for a successful organization are leadership style and competency (J. Rodney Turner and Ralf Muller, 2005). The five major functions of leadership are categorized as follows (Joel DiGirolamo, 2010).

- Create a vision and focus on it.

- Set up a high performance team.

- Keep the team motivated.

- Maintain a good rapport with people around to make sure they are aware about the information needed.

- Satisfy employees to minimize attrition

Leadership is defined in many numbers of studies on the subject. These leadership definitions are not common for all leaders for all situations. Hence lot of research was undertaken to identify what effective leaders do?. For many years traits have not been given importance for an effective leadership, however study on leadership have proven that the aspect of personality are also important for effective leadership such as dominance, extraversion, sociability, self confidence, high levels of energy and resilience. Wisdom and self awareness of a leader helps to a great extent in influencing the followers (Jeannet Weyers, 2010). Conger's research (Conger, J., 1992) explains that leaders can be groomed than being discovered by understanding the importance of planned development (John Davenport, 2008). Knowing one's own personality type might help leaders to know and understand one self better. As understanding the personality type (MBTI Type) of oneself would help the leaders to see how their traits, skills and behaviors are shaped (Philip E. Burian, et al., 2014)

\section{Leadership Theories}

A glimpse of the leadership theories will help set the platform for further discussion.

Great man theory states that the leaders are born and not made. The inherent characteristics will surface based on 
the need. This theory went well with our historians and was named as "Great man theory" as in the earlier days the leadership role was taken only by male. This thought was redundant after lot of research and studies were done on leadership (Maj Earl Russel, 2011).

Trait theory approach was also one of the early theories of leadership. This approach focuses on the basic traits like physical and personal characteristic along with the competencies a leader should posses. It is based on the assumption that basic traits are the reason for the behavior of the leaders which are consistent in different situations. Similar to the Great Man theory, this approach states that leaders have characteristics that they are born with and it remains consistent for a long time (Fleenor, John W., 2011).

Contingency theory focuses on factors connected to environment which might determine the leadership style that would be most appropriate for a particular situation. Various factors includes - the leadership style, followers and the situation Situational theory emphasizes that the leaders will choose the best style of leadership based on the situation and the group to be influenced Behavioral theory states that leaders are' made and not born' which is opposite to the concept of Great man theory. It states that leadership skills can be learned and developed (Kendra Cherry, n.d).

Participative theory explains about the collective decision making abilities of a leader or shared influence of the subordinates in decision making. This leadership style would help in motivating the team members as their inputs are being considered and given due importance (Anit Somech, 2006).

\section{Discussion}

Fiedler's Contingency Theory explains about the relationship between leadership style and performance of the group during different situations. This theory is based on some decisive elements like behavior of the leader (i.e). Task based or relationship based, the leader's effective orientation based on the situation and leader member exchange (Encyclopedia of group processes and Intergroup Relations, n.d).There are three situational dimensions attached to the effectiveness of a leader namely Leader member relations where it determines the subordinate's loyalty, dependability and support, Task structure depending on the subordinates routine jobs and position power where the leaders' authority is displayed. All the three situational dimensions help leaders in having a situational control. Managers having favorable relationship with subordinates would be able to have more task structure and reward or punish their employees without any issues (Bolden et al., 2003). In Fiedler's model leadership effectiveness is determined based on relationship between the style of the leader and the working environment of that leader. Leadership style will vary based on the personality styles of a leader and the working environment will be based on the situational aspects which will enable a leader to influence his or her followers (Patrich Antoine, n.d).

The leadership styles and contingency theories play a significant role in the literature pertaining to leadership (Shaun Killian, 2007). Leaders have to know how their leadership styles influence the performance of their followers. This might have both positive and negative impact on their followers for example: being supportive and consistent/being inconsistent/being unsupportive and inconsistent. Hence the leadership styles and contingency theories dominate the literatures on leadership (Warrick, n.d). Literatures also reveal that one of the most important functions of a leader is to monitor team performance and forecast the impact of the environment conditions that might have an effect on the team's performance. Thereby being able to think of preventing action in case of negative effect (Peter d. Bachiochi, Steven g. Rogelberg, Matthew s. O'connor \& Allison e. Elder, 2000).

Although there were several studies made, which concluded that there is no momentous relationship between leadership styles and personality types. Pearman, Roger and Fleenor (1997) observed a strong relationship between the psychological types and leadership behavior which was re-affirmed by using Myers Briggs Type Indicator (MBTI) for understanding the type preferences and reflections of a leader. Hence this study is an attempt to bring out the relationship between situational leadership and MBTI. Literature also talks about the importance of self awareness in a managerial career development and the findings reported that there is a relationship between the self awareness and the managerial career development process. The instruments used for this study was 360-degree feedback and personality inventories (McCarthy, A. \& N. Garavan, 1999). The inferior function is the one we least prefer to be used hence it comes into picture during circumstances like when an individual's energy levels are very low, drained, at times of stress ,Illness, fatigue ect this function is used which would not be that individual at all (Quenk, 2002).

The research has emphasized that knowledge on Myers Briggs Type Indicator (MBTI) will help leaders to understand the areas to be worked on while paying attention to employees needs and potential development areas. The understanding of four mental processes in Jung Theory gives information on energy, data collection, 
decision making, and orientation as these are the more critical areas in identifying what is required to make Blanchard's model more relevant. Hence linking MBTI and Situational leadership will give good insight to employees about self and others (CPP, n.d).

\section{Conceptual Model}

\subsection{Leadership Styles}

The situational leadership theory was developed by Paul Hersey and Ken Blanchard in 1969 proposes that effective leadership depends on the ability of the leader to change his or her behavior to suit the situation. The task and relationship behaviors are called directing and supporting behaviors. Hersey and Blanchard (1977) highlighted four different types of leadership behavior namely-telling (S1-high directive, low supportive), selling (S2-high directive, high supportive), participating (S3-low directive, high supportive), and delegating (S4-low directive, low supportive).

\subsection{Readiness Levels}

The role of an leader is to continuously monitor and acclimatize their leadership behavior to each follower's task maturity (i.e) Readiness Levels like R1, R2, R3 and R4. R1 being low maturity on performing a task and R4 being high on performing a task (Module 16, Update). According to situational leadership theory, successful leadership lies in choosing an appropriate leadership style based on the readiness level of the followers. The importance of followers in determining the effective leadership style is because it is follower who accept or reject a leader. The term readiness level means the ability and willingness to perform a specific task. The Situational leadership focuses on flexible leaders using appropriate behavioral responses at various situations. (Yaser mansour almansour, 2012).

\subsection{MBTI Types of Leader}

MBTI is a psychological instrument developed by Isabel Briggs Myers and her mother, Katharine Cook Briggs, this has been used by people around the world over 60 years to understand their personality and interests. They created 16 types with the description explaining individual's personality (Joseph, 2009). The report will also help in understanding the differences of each type. These personality types are exhibited by four letters based on their four preferences namely Extroversion/Introversion (E/I), Sensing/Intutive (S/N), Thinking/Feeling (T/F), Judging/Perceiving (J/P). The terms used, have a technical meaning related to MBTI rather than the word by itself (CPP, 2009). This instrument helps to a great extent for leaders in leading virtual teams which indeed has been a great challenge because of less interaction between the leaders and subordinates. A leader has to know his subordinates in order to keep them motivated so as to change his/ or her leadership style for getting the task done and ensuring their subordinates stay motivated. In this regard knowing the MBTI personality type of their subordinates will help the leaders lead effectively (Pearl, 2001). On the other hand knowing the MBTI type of a leader is essential for leadership development. Considerable research was done on the self awareness of a leader for enhancing their leadership skills. Through MBTI, leaders get a chance to assess their preferences that might impact their leadership styles (Kathleen Hanold Watland, 2009).

\subsection{Leadership Styles}

According to (Hal F. Cunnyngham, 2001). leadership style might be appropriate, over leading (subordinates feel leaders are over doing) or under leading(subordinates feel leaders are not giving them the required guidance) (Hal F. Cunnyngham, 2001) to their followers at various readiness levels.

On the basis of review of literature following conceptual framework is developed and presented below:

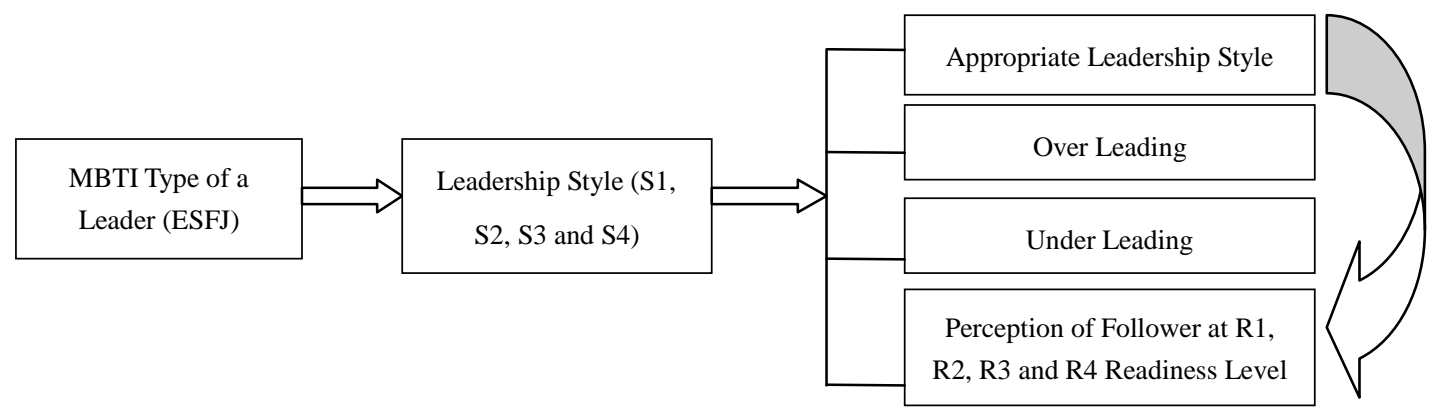

Figure 1. Conceptual framework 


\section{Research Methodology}

\subsection{Selection of the Study}

The purpose of this research is to bring out the relationship between MBTI and situational leadership, importance of knowing the MBTI type for a leader, thereby develop an instrument around this which would enable the leaders to understand their leadership style better.

\subsection{Research Design}

The design used for this study was experimental where the results were observed for a predicted outcome. It is an attempt made to test the hypothesis and arrive with the conclusion explaining the relationship between the dependant and independent variables of the study.

Research Area: Studying the Impact of Psychological Type and Leadership Development.

Research Design: Experimental Research

\section{Variable: MBTI}

Dependant Variable: Situational leadership

\subsection{Sampling}

Population: Employees having team members

Sample Size: 313

Sampling method: Convenient Sampling

\subsection{Data Collection}

Type of Data: Primary Data

Tools: Observation and Questionnaire

\subsection{Instrument Development}

The research was based on the qualitative and quantitative methodology. An instrument was developed based on preferences of individuals and their leadership styles at consideration of leaders at various situations. This questionnaire focused on the factors like leadership style, MBTI preference of leaders, readiness levels of followers, situations and followers perception about the leaders.

The results of this instrument were compared with the 360 feedback of individual leaders.

In the quantitative approach, the key instrument is a structured questionnaire. It consisted of the following sections.

1) Demographic data;

2) Likert scale (strongly agree to strongly disagree) was used to measure the leadership styles.

Pilot testing was conducted for fifty respondents and appropriate changes were made in the layout and content for easy readability and comprehension.

On the basis of extensive literature review, the variables for the questionnaire were identified. The questionnaire was validated by administering it on five successful and established entrepreneurs to identify any gaps in the literature review.

\subsection{Cronbach Reliability}

Validity of this instrument was assured through a test run with various stake holders and certified people in situational leadership. Reliability of the instrument was tested by Cronbach's alpha statistic with the help of SPSS Version 16. The values for all the factors were over 0.7 proving that the data is suitable for research. After this the questionnaire was extended to the rest of the sample.

Researchers have revealed that knowing one's own MBTI type will enable the person to be aware of his or her leadership preferences which in turn might help in identifying appropriate style of leadership to be adopted with the followers (Richard J. Wester, n.d). It has also been suggested that task oriented leaders (i.e) ' $\mathrm{T}$ 'would be more preferred for an immature organization and a relationship oriented (i.e) 'F' more appropriate for matured organization (M. P. Marty Ludlum, 2012).

Having explained about the situational leadership and MBTI, if a leader knows his/her MBTI personality type along with the situational leadership concept, it will help in understanding their leadership style applied to 
followers at various readiness levels R1,R2,R3 or R4 (Hal F. Cunnyngham, 2001), for example the study shows that the introverted leader could be a person more engaged in listening deep conversation, focused and organized (Anna Emanuelsson and Sandra Lindqvist, 2014) Their leadership style might be appropriate, over leading (subordinates feel leaders are over doing) or under leading (subordinates feel leaders are not giving them the required guidance) (Erika Hayes James and Lynn Perry Wooten, 2011) to their followers at various readiness levels. Understanding this will enable a leader to adjust their leadership style according to the readiness levels of the followers which helps in achieving high leader member exchange.

For example: if a leader's MBTI profile is ESFJ his or her leader ship type will be more appropriate to R3 because ESFJs would be highly interested in two way communication and will not be guiding their subordinates.R3 are able but unwilling hence they need more of supportive behavior in order to stay motivated. These leaders will come across as under leading for followers at R1 and R2 as they would need more of direction than supportive leadership style. For R4 followers they will be experienced as over leading because of their more of supportive behavior.

In order to understand the relationship between MBTI and situational leadership, a questionnaire was developed and circulated to group of leaders having reportees. These leaders had already taken the MBTI test and were aware of their personality style. In Parallel there was a type description written for all the 16 MBTI types based on their leadership styles at different readiness levels like R1, R2, R3 and R4.

This questionnaire was tested with 313 individuals out of which for 241 leaders the results were matching (i.e) the questionnaire helped in knowing their leadership style for their followers at various readiness levels. This was also validated against their 360 feedback for more clarity and was matching with those reports as well.

\section{Findings}

As a leader hold a major responsibility of leading others. This becomes a biggest challenge as the end result or the output depends on the performance of their followers. This research is an attempt to find a solution. As depicted in the above Fig: 1 and from the empirical study, if a leader knows his MBTI personality type along with the situational leadership concept, it will help him understand his/her leadership style applied to followers at various readiness levels $\mathrm{R} 1, \mathrm{R} 2, \mathrm{R} 3$ or R4 are perceived as his or her leadership style is appropriate, overleading (subordinates feeling leaders are over doing) or under leading(subordinates feel leaders are not giving them the required guidance) to their followers. Understanding this will enable a leader to adjust his/her leadership style according to the readiness levels of the followers which helps in achieving high leader member exchange both in-group and out-group situations.

For example: Below in the table 1 are the results for S1 leadership style and R1 readiness level from the study made with 313 managers.

Table 1. MBTI and leadeship style (S1)

\begin{tabular}{|c|c|c|c|c|c|c|}
\hline & \multirow[b]{2}{*}{ MBTI } & \multicolumn{2}{|c|}{ Unstandardized Coefficients } & \multirow{2}{*}{$\frac{\text { Standardized Coefficients }}{\text { Beta }}$} & \multirow[b]{2}{*}{$\mathrm{T}$} & \multirow[b]{2}{*}{ Sig. } \\
\hline & & B & Std. Error & & & \\
\hline \multirow[t]{5}{*}{1} & (Constant) & -1.143 & .391 & & -2.921 & .004 \\
\hline & E I computed value & .011 & .003 & .182 & 3.661 & .000 \\
\hline & SN computed value & .019 & .004 & .263 & 5.316 & .000 \\
\hline & TF computed value & .023 & .003 & .337 & 6.820 & .000 \\
\hline & JP computed value & .010 & .003 & .176 & 3.533 & .000 \\
\hline
\end{tabular}

a. Dependent Variable: S1 STYLE.

There is a strong relationship between the psychological types and leadership behavior which was reaffirmed using MBTI for understanding the type preferences and reflections of a leader. The researches have emphasized that knowledge on MBTI will help leaders to understand the areas to be worked on while paying attention to employee needs and potential development areas. The understanding of four mental processes in Jung Theory gives information on energy, data collection, decision making, and orientation as these are the more critical areas 
in identifying what is required to make Blanchard's model more relevant.

The results show a high beta value of 0.23 for TF variable and high T value of 6.820. It appears that the S1 type of leaders which is a dependent variable here have high score in TF preferences of their MBTI type (i.e) Most of the S1 leaders from the sample used here have significant scores among these two preferences. Hence knowing their MBTI preferences will help them to influence their subordinates based on their readiness levels (R1, R2, R3 or R4). For example: if their subordinates are at Readiness level one, they would need more of a directive style (T) of leadership that is more of task oriented than being supportive and encouraging $(\mathrm{F})$ so if the leader's MBTI preference is $\mathrm{F}$ instead of $\mathrm{T}$ the leaders have to flex a bit and give more directions and be more task oriented for effective leadership. Having detailed out about the highest beta value of TF variable the other three variables (EI, SN, and JP) have also shown that there is significance (Zumbo, B. D., \& Zimmerman, D. W, 1993).

Table 2. MBTI and readiness level (R1)

\begin{tabular}{llccccc}
\hline & & \multicolumn{2}{c}{ Unstandardized Coefficients } & \multicolumn{2}{c}{ Standardized Coefficients } \\
\cline { 3 - 5 } MBTI & & $\mathrm{B}$ & Std. Error & Beta & T & Sig. \\
\hline 1 & (Constant) & 4.232 & .157 & & 27.007 & .000 \\
& E I computed value & -.002 & .001 & -.062 & -1.450 & .148 \\
& SN computed value & -.015 & .001 & -.437 & -10.214 & .000 \\
& TF computed value & -.016 & .001 & -.502 & -11.730 & .000 \\
& JP computed value & .002 & .001 & .064 & 1.490 & .137 \\
\hline
\end{tabular}

$\mathrm{F}=60.802 ; \mathrm{R}$ Square $=.441$.

The above table 2 shows the results of multiple regression analysis between the MBTI preferences like EI, SN, TF and JP. The R square value clearly explains $44 \%$ of variance associated with Readiness level 1(R1). The F statistics is also highly significant $(\mathrm{F}=60.802)$ which confirms that the variables make a meaningful contributions to fit in to the regression model. The two independent variables SN and TF were significantly associated with Readiness level 1.

The most important variable was TF with highest Beta value of .502 and high $\mathrm{T}$ value of 11.730 explains that for readiness level 1 the most significant preferences that contributes to be an appropriate leader for R1 is TF preference followed by SN preference as have also shown that there is significance (Ferrari SLP, Cribari-Neto F, 2004).

Table 3. Leadership styles with respect to followers at readiness level 1

\begin{tabular}{lcccccc}
\hline Follower's Readiness Level & \multicolumn{5}{c}{ LEADERSHIP STYLE } \\
\hline Readiness Level 1(R1) & & S1 STYLE & S2 STYLE & S3 STYLE & S4 STYLE & Total \\
Appropriate & Count & 49 & 29 & 11 & 15 & 104 \\
& $\%$ & $75.40 \%$ & $67.40 \%$ & $7.90 \%$ & $22.70 \%$ & $33.20 \%$ \\
Over leading & Count & 14 & 14 & 2 & 0 & 30 \\
& $\%$ & $21.50 \%$ & $32.60 \%$ & $1.40 \%$ & $0.00 \%$ & $9.60 \%$ \\
Under leading & Count & 2 & 0 & 126 & 51 & 179 \\
& $\%$ & $3.10 \%$ & $0.00 \%$ & $90.60 \%$ & $77.30 \%$ & $57.20 \%$ \\
Total & Count & 65 & 43 & 139 & 66 & 313 \\
& $\%$ & $100.00 \%$ & $100.00 \%$ & $100.00 \%$ & $100.00 \%$ & $100.00 \%$ \\
\hline
\end{tabular}

According to Paul Hersey, "Situational Leadership ${ }^{\circledR}$ model S1 leadership style is inferred as "Telling" or "Directing". These leaders will be high on task and low on relationship. Mostly there will be a one way 
communication where the leaders defines what, how and when to do each task. These types of leaders are more appropriate to subordinates at readiness level $1(\mathrm{R} 1)$ as they will not be willing to do a task and will also not be able to do a task S1 leaders will be more task oriented and will have a more directive behaviour and low on relationship (support)

The above table 3 shows that there were 49 people with S1 type of leadership style more appropriate to Readiness level 1(R1) subordinate this was validated against the 360 feedback for these leaders. There were also 29 S2 type leaders who came across as appropriate leaders for readiness level 1(R1) subordinates. On the other hand the $126 \mathrm{~S} 3$ leaders and $51 \mathrm{~S} 4$ leaders came across as over leading leaders for this readiness level 1(R1) as those leaders will not focus much on the tasks and their leadership styles are nor directive and task oriented.

\section{Conclusion}

The selection of an appropriate leadership style depends on the situation as well as the personalities of leaders for influencing. Knowing and understanding the different types of personality preferences of a leader, can form the basis of a leadership style which will result in high probability of success. This will also help the leaders to flex their leadership styles appropriately as and when there is a need. It is found that an leadership style need not be inborn, but can be developed.

\section{References}

Anit, S. (2006). The Effects of Leadership Style and Team Process on Performance and Innovation in Functionally Heterogeneous Teams. Journal of $\quad$ Management, $\quad 32(1) . \quad 132-157$. http://dx.doi.org/10.1177/0149206305277799

Anna, E., \& Sandra, L. (2014). Leadership of Introverts. Blekinge Institute of Technology, School of Management, MBA.

Aric, H. (2007). Leadership Thought Journal. Capella University.

Bolden et al. (2003). A Review of Leadership Theory and Competency Frameworks. Center of Leadership studies, University of Exeter. CGSC Class 11-02 Conference (pp. 183-211).

Bruce, E. W., \& Kathleen, P. (2006). An Integrative Definition of Leadership. International Journal of Leadership Studies, 1(2), 6-66.

Conger, J. (1992). Learning to lead: The art of transforming managers into leaders. Jossey-Bass, San Francisco.

CPP (n.d). Using the Myers - Briggs $®$ Instrument with Blanchard's Situational Leadership II Assessment. MYERS-BRIGGS®/SLII® GUIDE.

CPP. (2009). Effectiveness: a multivariate analysis of observational variables and the MBTI. Myers-Briggs Type Indicator Interpretive Report.

Encyclopedia of group processes and Intergroup Relations. (n.d). Contingency Theories of Leadership. SAGE Publication,Inc.

Erika, H. J., \& Lynn, P. W. (2011). Leading Under Pressure: From Surviving to Thriving Before, During, and After a Crisis. The Member Connector, International Leadership Association.

Fleenor, J. W. (2011). Trait Approach to Leadership. Encyclopedia of Industrial and organisational Psychology. SAGE Publication.

Hal, F. C. (2001). A study of the relationships between personality as indicated by the myers briggs type indicator and leadership strengths and weaknesses as identified by skillscope. University of North Texas.

Hersey, P., \& Blanchard, K. H. (1977). Management of Organizational Behavior (3rd ed.). New Jersey/Prentice Hall: Utilizing Human Resources.

J. Rodney, T., \& Ralf, M. (2005). The Project Manager's Leadership Style as a Success Factor on Projects: A Literature Review. Project Management Journal.

Jeannet, W. (nd). Importance of leadership capacity versus competence: a case study. Australian Journal Of Management \& Organisational Behaviour, 5(1), 117-128.

Joel, D. (2010). The art, psychology, and science of management-an integrated approach. Leaders and the Leadership Process, Turbocharged Leadership.

John, D. (2008). Jay conger's "learning to lead": a book review. Business Intelligence Journal.

Joseph, D. T. (2009). The correlation between Myers-Briggs type and preparedness for leadership. Prescott 
Valley.

Kathleen, H. W. (2009). The Myers-Briggs Type Indicator as a Tool for Leadership Development in Management Education Programs: What's Type Got to Do with It? Myers-Briggs Type Indicator as a Tool for Leadership Development.

Kendra, C. (n.d). Leadership Theories: The 8 Major Leadership Theories. Retrieved from http://psychology.about.com/od/leadership/p/leadtheories.htm

M. P. Marty, L. (2012). Mustang Journal of Business \& Ethics, 3.

Maj, E. R. (2011). Leadership Theories and Style: A Transitional Approach. Military Leadership Writing Competition, CGSC Class 11-02.

McCarthy, A., \& Garavan, N. (1999). Developing self-awareness in the managerial career development process: the value of 360-degree feedback and the MBTI. Journal of European Industrial Training, 23(9), 437-445. http://dx.doi.org/10.1108/03090599910302613

Patrich, A. (n.d). Fiedler's Contingency Theory of Leadership. University of St.Francis.

Pearl, Y. (2001). Leadership and the Myers-Briggs type indicator. Art McCormick.

Pearman, R. R., \& John, W. F. (1997). Sixteen patterns of leadership.

Peter D. B., Steven G. R., Matthew, S. O., \& Allison, E. E. (2000). The qualities of an effective team leader. Organization development journal, 18(1).

Philip, E. B. et al. (2014). Leadership Systems Model: An Integration Of People, Process, And Behaviors In A Dynamic And Evolving Environment. The Clute Institute International Academic Conference. Munich, German.

Richard, J. W. (n.d). Personality Typing and Leadership. Retrieved from http://www.uscg.mil/leadership/resources/leadershipnews_cdrwester.pdf

Shaun, K. (2007). The ABC of Effective Leadership. Australian Leadership Development Centre.

Warrick. (n.d). Leadership Styles and Their Consequences. University of Colorado, Co 80908.

Yaser, M. A. (2012). The relationship between leadership styles and motivation of managers conceptual framework. Journal of arts, science \& commerce.

Zumbo, B. D., \& Zimmerman, D. W. (1993). Is the selection of statistical methods governed by level of measurement? Canadian Psychology, 34, 390-400. http://dx.doi.org/10.1037/h0078865

\section{Copyrights}

Copyright for this article is retained by the author(s), with first publication rights granted to the journal.

This is an open-access article distributed under the terms and conditions of the Creative Commons Attribution license (http://creativecommons.org/licenses/by/3.0/). 